\title{
Monitoring rodents movements with a biomarker around introduction and feeding foci in an urban environment in Tanzania
}

Author(s): Katrine Mohr , Herwig Leirs , Abdul Katakweba , and Robert Machang'u Source: African Zoology, 42(2):294-298. 2007.

Published By: Zoological Society of Southern Africa

DOI: http://dx.doi.org/10.3377/1562-7020(2007)42[294:MRMWAB]2.0.CO;2

URL: http://www.bioone.org/doi/

full/10.3377/1562-7020\%282007\%2942\%5B294\%3AMRMWAB\%5D2.0.CO\%3B2

BioOne (www.bioone.org) is a nonprofit, online aggregation of core research in the biological, ecological, and environmental sciences. BioOne provides a sustainable online platform for over 170 journals and books published by nonprofit societies, associations, museums, institutions, and presses.

Your use of this PDF, the BioOne Web site, and all posted and associated content indicates your acceptance of BioOne's Terms of Use, available at www.bioone.org/page/terms_of_use.

Usage of BioOne content is strictly limited to personal, educational, and non-commercial use. Commercial inquiries or rights and permissions requests should be directed to the individual publisher as copyright holder. 


\title{
Monitoring rodents movements with a biomarker around introduction and feeding foci in an urban environment in Tanzania
}

\author{
Katrine Mohr ${ }^{1 *}$, Herwig Leirs ${ }^{1,2^{*}}$, Abdul Katakweba ${ }^{3}$ \& Robert Machang ${ }^{3}{ }^{3}$ \\ ${ }^{1}$ Danish Pest Infestation Laboratory, University of Aarhus, Faculty of Agricultural Sciences, Department of Integrated \\ Pest Management, Skovbrynet 14, DK-2800 Kgs. Lyngby, Denmark \\ ${ }^{2}$ Evolutionary Biology Group, University of Antwerp, Groenenborgerlaan 171, B-2020 Antwerpen, Belgium \\ ${ }^{3}$ SUA Pest Management Center, Sokoine University of Agriculture (SUA), P.O.BOX 3110, Morogoro, Tanzania \\ Received 19 March 2007. Accepted 29 June 2007
}

Rodents are of concern as reservoirs and transmitters of pathogens that cause zoonotic and other diseases in domestic animals and humans. The contact between wild and urban rodent fauna is increasing in expanding cities in Africa, and this arguably increases the risk of disease transmission to urban populations. When rodents from rural areas are accidentally introduced into cities and encounter urban rodents, for example, in markets, grain mills and butcheries, there is a potential that pathogens are transferred between rural and urban rodent populations. Using a non-toxic biomarker, Rhodamine B (RB), we investigated the distances over which rodents are active around such potential introduction sites. Animals feeding at such sites were traced up to $100 \mathrm{~m}$ distant within a period of 10 days. We found that $\mathrm{RB}$ is a practical alternative for studying rodent movements. These results may be useful in designing management strategies to reduce the risk of the introduction of new rodent-borne pathogens in cities.

Key words: rhodamine B, biomarker, rodents, pest management.

$\mathrm{R}$ odents cause numerous problems as agricultural pests but also act as reservoirs and transmitters of pathogens, which is particularly acute in developing countries (e.g. Gratz et al. 1997; Dalu \& Feresu 1997; Kumar et al. 1997; Kilonzo et al. 1997; Stenseth et al. 2003). While such risks were previously deemed to be worst in rural settings (Fiedler 1988), there is a growing concern of the situation in cities (Gubler 1998). Concurrent with the expansion of cities, often with poor or absent sewage systems in the periphery and the deterioration of infrastructure in old city centres, new environmental conditions appear that are favourable to rodents. There is an increased risk of rodents from rural areas encountering rodents in urban areas because of the expanding city approaching the rural area geographically, the increased long-distance

*Authors for correspondence.

E-mail: herwig.leirs@ua.ac.be or katrine.mohr@get2net.dk transport of goods to be marketed in the city and/or the development of agricultural activities within the city environment (Dongus 2000). Rodents from rural areas may carry pathogens that are normally absent in the urban environment and vice versa (e.g. the plague bacterium Yersinia pestis, arenaviruses, mycobacteria that use wild rodents as reservoirs, some groups of Leptospira) (Gubler 1998). The possibility of rural rodents being translocated into cities is highest at sites such as markets and grain mills, where goods have been transported from rural areas. Moreover, the conditions at these central sites are usually suitable for rodent survival. Urban rodents may then acquire pathogens from the rural rodents and spread them further through their movements. Management of rodents at sites with high activity of goods transportation should therefore take into account the ranges of the rodents that forage there. Brown rats can move up to several kilometres in the course of a single night (Taylor \& Quy 1973), but it seems unlikely that they would cover such distances in urban settings. The aim of this study was, therefore, to assess the movement/dispersal of rodents to and from locations that are possible sources of new pathogens in the urban setting of Morogoro, Tanzania. Another aim of the study was to evaluate the use of Rhodamine $B$ as an alternative for studying movements of rodents in an urban environment.

To monitor rodent movements, we used baits mixed with the biomarker Rhodamine B (RB). When this chemical is ingested in low, non-lethal doses, mammals will deposit it in their tissues (hair, teeth and bones) where RB can be detected as a fluorescent dye (Southey et al. 2002). Several studies have shown that bait marked with RB is palatable and accepted by rodents (Fisher 1999; Southey et al. 2002; Papillon 2002; Jacob et al. 2003). Rhodamine B marks hairs and claws of mammals 
and has been shown to last up to 143 days after ingestion in the whiskers of Myocastor coypus (Fichet-Calvet 1999).

This study was carried out from May-July 2004 in the city of Morogoro, Tanzania (06 $51^{\circ} \mathrm{S}$, $\left.37^{\circ} 38^{\prime} \mathrm{E}\right)$. Prior to carrying out our fieldwork, we conducted a pilot study in the laboratory to test the willingness of common rodent species to eat the marked bait. Eight wild-caught Mastomys natalensis (A. Smith, 1834) and 10 Rattus rattus (Linnaeus, 1758) were anaesthetized, whisker samples were taken to detect background fluorescence, and the rats were then placed in individual cages. Four $M$. natalensis and five $R$. rattus were provided with a regular bait (mix of peanut butter and maize bran). The remaining rats were free to choose between the regular bait and regular bait mixed with $0.2 \%$ RB (Sigma-Aldrich Denmark A/S, Product no R6626-25G). This concentration is nonlethal and is known to result in detectable fluorescence in mouse whiskers (Willekens 2003). Consumption of each type of bait was recorded every morning for three consecutive days. One week later the rodents were anaesthetized, and a minimum of six whiskers were removed from either side. The whiskers were rinsed in $70 \%$ ethanol, placed on a single glass microscope slide in a drop of water under a cover slip, and investigated under a fluorescence microscope (Axioscope Zeiss) fitted with a reflected light fluorescence attachment $(530-585 \mathrm{~nm})$ and at $\times 10$ magnification. Hair samples were recorded positive for RB marking when a bright orange fluorescence was observed along the hair shaft or in the follicle. Furthermore, observations of the same hairs were carried out in a blind test with the observer not knowing which hairs belonged to control or experimental animals.

For the field study, the same RB-bait was placed at three different sites in Morogoro municipality namely, markets, slaughterhouses/butcheries, and grain stores/mills. At each site three different focal sites were identified, making a total of nine sites in total.

- Markets: Soko Kuu, Mwembesongo and Saba Saba

- Butcheries: Chamwino, Kilakala and Msamvu Central Slaughterhouse

- Mills: Misufini, Msamvu and Tanesco

Bait (50 g) marked with RB was put in empty half coconut shells and placed within a $25-35 \mathrm{~m}^{2}$ area where rodents were most likely to feed or hide. Every morning, consumption was noted at each feeding station and replenished where necessary.
This was repeated for four consecutive nights. The location of bait stations was recorded by reading coordinates from a hand-held GPS.

Five days after the last feeding night, traps baited with a peanut butter and maize bran mix were placed at varying distances from the $\mathrm{RB}$ feeding sites i.e. $0 \mathrm{~m}, 20 \mathrm{~m}, 50 \mathrm{~m}, 100 \mathrm{~m}$, and $200 \mathrm{~m}$. At each distance, we placed 12 traps of different types at sites where most rodent activity was expected. The sites were identified based on local peoples' observations of rodent activity, or from signs of rodents, e.g. faeces, rodent pathways or footprints.

Traps were placed at approximately two to five metres apart in lines or clusters. The trapping locations closest to the baiting points ( 0 to $20 \mathrm{~m}$ ) mostly consisted of habitat similar to the chosen bait locations (i.e. market areas, butcheries, and grain stores) whereas the trapping locations further away (50 to $200 \mathrm{~m}$ ) varied from dense building areas to fallow land. This means that the habitat between the trapping locations varied considerably. Roads crossing between trapping locations were avoided where possible. Traps were placed inside or around houses as well as in uncultivated surroundings.

Removal trapping of rodents was carried out. Traps were checked every morning and captured animals were collected. Trapping was repeated for four consecutive nights.

We used a combination of Sherman LFA live traps $(7.5 \times 9.0 \times 23.0 \mathrm{~cm}$, HB Sherman Traps Inc, Tallahassee, U.S.A.), home-made wooden box live traps, Havahart traps, traditional funnel traps and snap traps in order to catch diverse species of rodents. Each day we set 60 traps at each location (i.e. 180 traps per night) for 12 nights, giving a total of 2160 trap-nights. The location of the traps was recorded using a GPS.

Captured rodents were euthanized in a glass jar containing a cotton wool ball with Isoflurane ${ }^{\circledR}$ (Schering-Plough Animal Health). At least six nasal whiskers, including the follicle, were removed with tweezers from both sides of the snout. All individuals were subsequently used for tissue sampling (blood, kidney, heart, lung and spleen) for an ongoing study on the role of rodents as carriers of zoonotic diseases in urban and periurban areas.

\section{PILOT STUDY}

None of the rodents showed fluorescence in the whiskers or follicles before the experiment. Over a 
Table 1. The total number of individuals trapped with a positive Rhodamine B signal by species and trapping distance.

\begin{tabular}{|c|c|c|c|c|c|c|}
\hline \multirow[b]{2}{*}{ Species } & \multicolumn{6}{|c|}{ Distance } \\
\hline & $0 \mathrm{~m}$ & $20 \mathrm{~m}$ & $50 \mathrm{~m}$ & $100 \mathrm{~m}$ & $200 \mathrm{~m}$ & Total \\
\hline Cricetomys gambianus & $2 / 2$ & $2 / 3$ & $0 / 0$ & $0 / 1$ & $0 / 5$ & $4 / 11$ \\
\hline Crocidura sp. & $1 / 1$ & $0 / 0$ & $0 / 5$ & $0 / 10$ & $1 / 4$ & $2 / 20$ \\
\hline Rattus rattus & $2 / 20$ & $1 / 2$ & $2 / 14$ & $0 / 7$ & $0 / 3$ & $5 / 46$ \\
\hline Rattus norvegicus & $1 / 2$ & $0 / 0$ & $0 / 0$ & $0 / 0$ & $0 / 1$ & $1 / 3$ \\
\hline Mastomys natalensis & $0 / 0$ & $0 / 0$ & $0 / 1$ & $1 / 12$ & $0 / 1$ & $1 / 14$ \\
\hline Mus sp. & $3 / 3$ & $1 / 9$ & $0 / 1$ & $0 / 10$ & $0 / 13$ & $4 / 36$ \\
\hline Grammomys dolichurus & $0 / 0$ & $0 / 0$ & $0 / 1$ & $0 / 0$ & $0 / 0$ & $0 / 1$ \\
\hline \multirow[t]{2}{*}{ Total } & $9 / 28$ & $4 / 14$ & $2 / 22$ & $1 / 40$ & $1 / 27$ & $17 / 131$ \\
\hline & $32 \%$ & $29 \%$ & $9 \%$ & $3 \%$ & $4 \%$ & \\
\hline
\end{tabular}

three-night average, $24 \pm 17 \%$ of the total bait consumed by $R$. rattus consisted of RB-marked bait. The daily average intake was between 1.83 and $6.07 \mathrm{~g}$ of the control bait and between 0.37 and $1.47 \mathrm{~g}$ of the RB-marked bait over three days. For $M$. natalensis the average consumption of RBmarked bait was $54 \pm 14 \%$ of the total bait intake with an average daily intake of $1.43-3.63 \mathrm{~g}$ of control bait and 2.07-3.37 g of the RB-marked bait. None of the test animals showed external signs of $\mathrm{RB}$ on their fur or paws; however, all of the test animals showed fluorescence in at least $50 \%$ of their whiskers when investigated under UV light using a fluorescence microscope. These results show that the two rodent species used in the pilot study were willing to eat the RB-marked bait. Still, $R$. rattus ate the marked bait less readily than $M$. natalensis. Thus, even at equal proportions of animals that would be foraging at the baiting point, the probability of finding RB-positive $M$. natalensis would be greater. Thus, the willingness of a species to consume RB-marked bait should be taken into account when using $R B$ marker and this may become problematic if a study does not focus on a single species.

\section{FIELD STUDY}

In total, 131 small mammals were captured during the field study. The number of individuals captured varied between locations: Mills/grain stores: Tanesco $(n=16)$, Msamvu $(n=24)$, Misufini $(n=11)$; Markets: Mwembesongo $(n=22)$, Saba saba $(n=1)$, Soko kuu $(n=2)$; Butcheries/slaughterhouse: Msamvu Slaughterhouse $(n=16)$, Kilakala $(n=25)$ and Chamwino $(n=14)$.

The two dominant species were $R$. rattus $(n=46$; $35.1 \%)$ and $M u s$ sp. $(n=36 ; 27.5 \%)$, which together comprised $62.6 \%$ of the total number of rodents trapped. Most $R$. rattus were trapped close to the baiting points $(0-50 \mathrm{~m})$; whereas the number of Mus sp. slightly increased with distances over $50 \mathrm{~m}$ (Table 1). Other animals trapped were shrews $(n=20 ; 15.3 \%)$, M. natalensis $(n=14 ; 10.69 \%)$, Cricetomys gambianus $(n=11 ; 8.4 \%), R$. norvegicus $(n=3 ; 2.3 \%)$ and Grammomys dolichurus $(n=1$; $0.76 \%)$.

Rattus rattus was the most common species near the baiting points (in or near buildings) although it was absent at some of the studied distances. By contrast, $M$. natalensis was common at some sites (located in urban farmland) but was not captured at all near the baiting points. Keeping in mind the natural habitats of the two species, these findings were not surprising. Mus sp. was the most common over larger distances where traps were mainly placed in residential houses. A thorough understanding of species composition and distribution within urban habitats is, therefore, necessary before setting up a RB study.

Among the trapped animals, 17 individuals (13\%) showed RB fluorescent marking in the whiskers under the fluorescence microscope. None of the animals showed any external signs of RB bait consumption. Table 1 shows the seven different species, their site distance, and the number of RB-positive individuals. The percentage of animals showing positive RB marking decreased as the distance from the bait point increased. At $0 \mathrm{~m}, 32 \%$ of the trapped animals were found to have RB in the whiskers, showing evidence of marked bait consumption. However, $3.7 \%$ of the animals (one individual) trapped $200 \mathrm{~m}$ from the bait point showed RB fluorescence in the whiskers.

Figure 1 shows the proportion of RB-positive animals plotted against the distance from the bait 


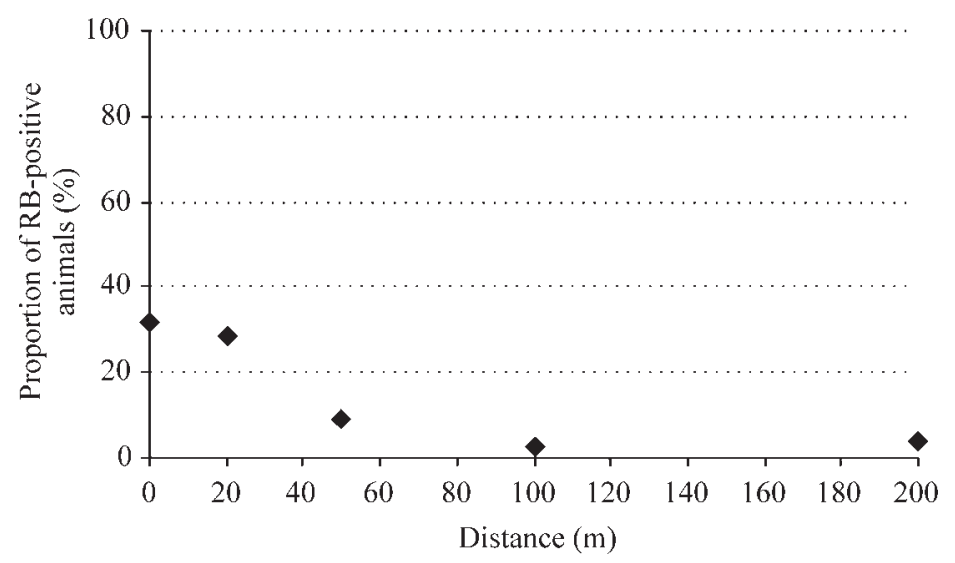

Fig. 1. The proportion of positive Rhodamine B animals trapped in relation to distance to feeding site.

point to the trapping point. The proportion of RBpositive animals decreases with increasing distance from the bait point. At $20 \mathrm{~m}$ to $50 \mathrm{~m}$ from the bait point, the proportion of RB-positive animals decreases markedly to below $5 \%$ at $100 \mathrm{~m}$.

Figure 2 shows the proportion of RB-positive individuals of the most abundant species $R$. rattus and Mus sp. The proportion of Mus sp. positive for $\mathrm{RB}$ reaches 0 at a distance of $50 \mathrm{~m}$. Rhodamine Bpositive $R$. rattus were found at a distance of up to $100 \mathrm{~m}$ from the baiting point. We observed an RB signal mark in a shrew that was trapped at $200 \mathrm{~m}$ from the baiting point. This was surprising since shrews generally move over much shorter distances with home ranges of $350-650 \mathrm{~m}^{2}$ (Ivanter \& Makarov 1994). Shrews, being insectivorous, would generally not eat large quantities of the bait used in this study. It is, therefore, unclear whether this RB-positive shrew indicated a genuine long distance over which this animal moved after eating the bait or whether its mark was due to 'secondary marking' by predating on large insects or small rodents that previously may have consumed marked baits and moved away, or due to other unspecific fluorescence (although there was no particular indication for the latter).

\section{CONCLUSIONS}

This study showed that the use of Rhodamine B as a bait marker is a practical alternative for the study of movements of urban rodents. Classical methods like capture-recapture (Krebs 1989) studies and telemetry both require the release of captured

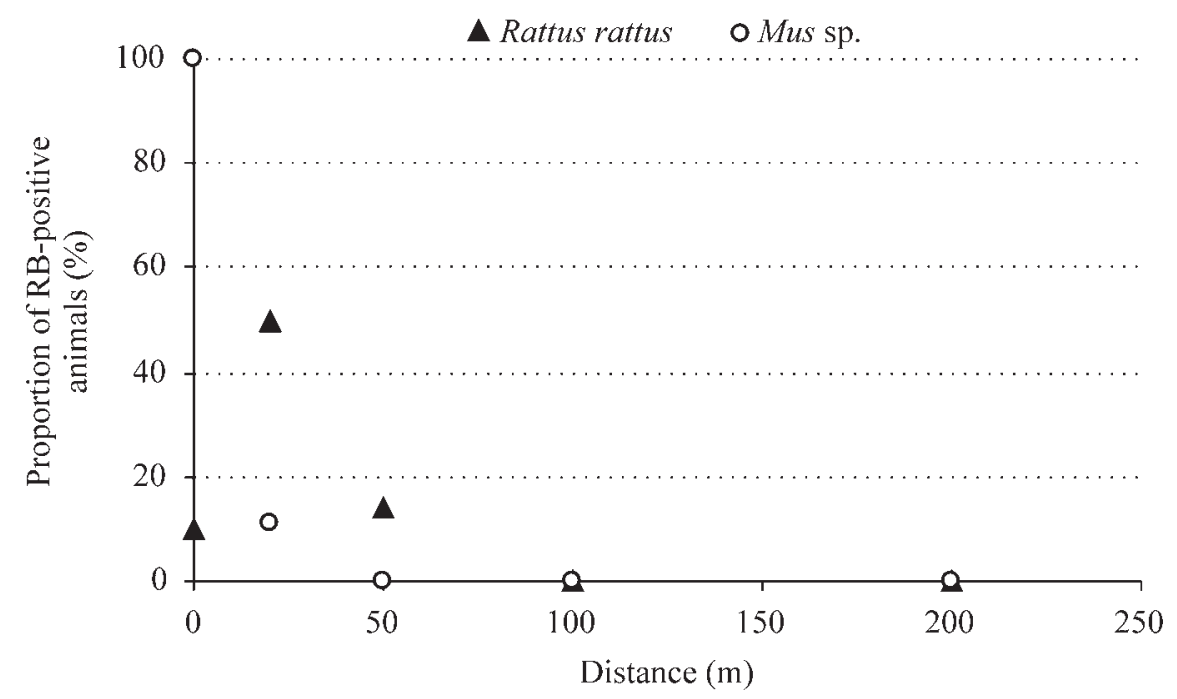

Fig. 2. The proportion of Rattus rattus and Mus sp. positive for Rhodamine B in relation to trapping distance. 
rodents. This procedure is unlikely to be accepted by many communities wishing to rid themselves of rats. Telemetry is also impractical in an urban environment because of the need to cross the properties of many different households during observation and the strong reduction of transmission ranges in high-density areas. The fluorescent bait marker method does not provide detailed information at the individual level, but does allow estimating minimum distances that are covered by animals from the baiting point. Nevertheless, our results also indicate some caveats. Earlier work with Rhodamine B baits took place mainly in fairly homogenous open landscapes (Taylor \& Quy 1973; Fisher 1999; Papillon et al. 2002). In an urban environment, there may be dramatic habitat differences, with very sharp borders over short distances, possibly resulting in completely different species compositions at different distances from the baiting point.

Jacob et al. (2003) stressed that the height of fence line vegetation, the protein content in the available food and the density of marked food pellets influenced the RB intake by Mus domesticus. We found that species composition may also affect the efficacy of the bait as a means of delivering the fluorescent marker to the animals.

The gradual decline in the proportion of RBpositive animals when moving away from the baiting points is a pattern that is consistent with our expectations. In the present study, despite the low total number of captures, the variety of habitats and the diversity of species, there is a clear indication that beyond $100 \mathrm{~m}$ from the baiting point the probability of finding rodents that had been at the baiting station the week before is small. Information about such movements in an urban setting is very useful for urban rodent management (Lambropoulos et al. 1999).

This work was carried out within the framework of the RATZOOMAN Project, supported by EU grant FP5-INCO-DEV ICA4-CT2002-10056. We very much appreciate the help of the SUA Pest Management Centre's field team in collecting and investigating the rats.

\section{REFERENCES}

DALU, J.M. \& FERESU, S.B. 1997. Domestic rodents as reservoirs of pathogenic leptospira on two City of Harare farms: preliminary results of bacteriological and serological studies. Belgian Journal of Zoology 127(suppl. 1): 105-112.

DONGUS, S. 2000. Vegetable production on open spaces in Dar es Salaam - Spatial changes from 1992 to 1999.
In: Urban Agriculture Notes. City Farmer, Canada's Office of Urban Agriculture, 39.

FICHET-CALVET, E. 1999. Persistence of a systemic labelling in fur and guard hairs by ingestion of Rhodamine B in Myocastor coypus (Rodentia). Mammalia 63: 241-244.

FIEDLER, L.A. 1988. Rodent problems in Africa. In: Rodent Pest Management, (ed.) I. Prakash, pp. 35-65. CRC Press, Boca Raton.

FISHER, P.M. 1999. Review of using Rhodamine B as a marker for wildlife studies. Wildlife Society Bulletin 27: 318-329.

GRATZ, N.G. 1997. The burden of rodent-borne diseases in Africa south of the Sahara. Belgian Journal of Zoology 127 (suppl. 1): 71-84.

GUBLER, D.J. 1998. Resurgent vector-borne diseases as a global health problem. Emerging Infectious Diseases 4(3): 442-450.

IVANTER, E.V. \& MAKAROV, A.M. 1994. The spatial structure of shrew populations (Sorex, Insectivora) and its correlation with the feed biomass in communities. Zoologichesky Zhurnal 73: 124-138. (Abstract only.)

JACOB, J., YLONEN, H., RUNICE, M.J., JONES, D.A. \& SINGLETON. G.R. 2003. What affects bait uptake by house mice in Australian grain fields? Journal of Wildlife Management 67: 341-351.

KILONZO, B.S., MVENA, Z.S.K., MACHANG'U, R.S. \& MBISE, T.J. 1997. Preliminary observations on factors responsible for long persistence and continued outbreaks of plague in Lushoto district, Tanzania. Acta Tropica 68: 215-227.

KREBS, C.J. 1989. Ecological Methodology. Harper and Row, New York.

KUMAR, K., JAMIL-UR-RAHMAN, S., SHARMA, S.K., GILL, K.S., KATYAL, R., KAUR, R., THOMAS, T.G., LAMBROPOULOS, S.A., FINE, B., PERBECK, A., TORRES D., GLASS, G.E., MC HUGH, P. \& DORSEY, E. 1999. Rodent control in urban areas, an interdisciplinary approach. Journal of Environmental Health 61: 12-17.

PAPILLON, Y., BUFFIERE, L. \& BUTTET, A. 2002 Rhodamine B as a collective marker for studying movements of small mammals. Acta Theriologica 47(4): 491-497.

SOUTHEY, A.K., SLEEMAN, D.P. \& GORMLEY, E. 2002. Sulfadimethoxine and Rhodamine B as oral biomarkers for European badgers (Meles meles). Journal of Wildlife Diseases 38: 378-384.

STENSETH, N.C., LEIRS, H., SKONHOFT, A., DAVIS, S.A., PECH, R.P., ANDREASSEN, H.P., SINGLETON, G.R., LIMA, M., MACHANG'U, R.S., MAKUNDI, R.H., ZHANG, Z.B., BROWN, P.R., SHI, D.Z. \& WAN, X.R. 2003. Mice, rats, and people: the bio-economics of agricultural rodent pests. Frontiers in Ecology and the Environment 1(7): 367-375.

TAYLOR, K.D. \& QUY, R.J. 1973 Marking systems for the study of rat movements. Mammal Review 3: 30-34.

WILLEKENS, N. 2003. Beweging en reservoirstatus van commensale knaagdieren in een stedelijke omgeving in Tanzania. M.Sc. thesis, University of Antwerp, Belgium. 